\title{
ON THE SOLUTION OF VARIATIONAL INEQUALITY PROBLEMS BY USING CUTTING PLANE METHODS
}

\author{
STEFAN M. STEFANOV
}

\begin{abstract}
In this paper, variational inequality problems (VIPs) defined by generalized monotone and pseudomonotone single-valued and multivalued mappings are considered. Some properties of generalized monotone and pseudomonotone mappings are established. The idea of cutting plane methods, developed originally for solving discrete optimization problems (in particular, integer linear programming problems), is applied for solving the considered VIPs.
\end{abstract}

Mathematics subject classification (2000): 49J40, 65K10, 90C33.

Key words and phrases: variational inequalities, classes of monotonicity, cutting plane methods.

\section{REFERENCES}

[1] R. ANDREANI, J. M. MartíneZ, Reformulation of variational inequalities on a simplex and compactification of complementarity problems, SIAM Journal on Optimization, 10, (3) (2000), 878 895.

[2] A. AUSLENDER, R. COMINETTI AND M. HADDOU, Asymptotic analysis of penalty and barrier methods in convex and linear programming, Mathematics of Operations Research, 22, (1997), 43 - 62.

[3] A. Auslender, M. Teboulle, Lagrangian Duality and Related Multiplier Methods for Variational Inequality Problems, SIAM Journal on Optimization, 10, (4) (2000), 1097-1115.

[4] A. Auslender, M. Teboulle AND S. Ben-TiBA, A logarithmic-quadratic proximal method for variational inequalities, Computational Optimization and Applications, 12, (1998), 31-40.

[5] A. Auslender, M. Teboulle AND S. Ben-TiBA, Interior proximal and multiplier methods based on second order homogeneous kernels, Mathematics of Operations Research, 24, (1999), 645-668.

[6] A. L. DONTCHEV, R. T. ROCKAFELLAR, Characterizations of strong regularity for variational inequalities over polyhedral sets, SIAM Journal on Optimization, 6, (1996), 1087-1105.

[7] F. FACCHINEI, C. KANZOW, Beyondmonotonicity in regularization methods for nonlinear complementarity problems, SIAM Journal on Control and Optimization, 37, (1999), 1150-1161.

[8] M. FuKushima, Equivalent differentiable optimization problems and descent methods for asymmetric variational inequality problems, Mathematical Programming, 53, (1992), 99-110.

[9] S. A. GABRIEL, J. J. MoRÉ, Smoothing of mixed complementarity problems, In: Complementarity and Variational Problems: State of the Art, M.C. Ferris and J.S. Pang, eds., SIAM, Philadelphia, 1997, pp. $105-116$.

[10] J.-L. GOFFIN, P. MARCOTTE AND D. L. ZHU, An analytic center cutting plane method for pseudomonotone variational inequalities, Operations Research Letters, 20, (1997), 1-6.

[11] D. KinderLehrer, G. StAMPACCHIA, An Introduction to Variational Inequalities and Their Applications, 2nd. ed., Classics in Applied Mathematics, vol. 31, SIAM, Philadelphia, 2000.

[12] HANS-JACOB LÜTHI, BENNO BÜELER, The analytic center quadratic cut method for strongly monotone variational inequality problems, SIAM Journal on Optimization, 10, (2) (2000), 415-426.

[13] O. L. MANGASARIAN, M. V. SOLODOV, Nonlinear complementarity as unconstrained and constrained minimization, Mathematical Programming, 62, (1993), 277-297.

[14] P. MARCotTE, J. P. DUSSAULT, A note on a globally convergent Newton method for solving monotone variational inequalities, Operations Research Letters, 6, (1987), 35-42. 
[15] Y. NESTEROV, J.-P. VIAL, Homogeneous analytic center cutting plane methods for convex problems and variational inequalities, SIAM Journal on Optimization, 9, (1999), 707-728.

[16] J. M. PENG, Equivalence of variational inequality problems to unconstrained optimization, Mathematical Programming, 78, (1997), 347-355.

[17] H.-D. QI, A regularized smoothing Newton method for box constrained variational inequality problems with $P_{0}$ - functions, SIAM Journal on Optimization, 10, (2) (2000), 315-330.

[18] L. QI, J. SuN, A nonsmooth version of Newton's method, Mathematical Programming, 58, (1993), 691-714.

[19] M. SOlodov, B. SvaITER, A hybrid projection-proximal point algorithm, Journal of Convex Analysis, 6. (1999), 59-70.

[20] M. V. Solodov, B. F. SvaIter, A trully globally convergent Newton-type method for the monotone nonlinear complementarity problem, SIAM Journal on Optimization, 10, (2) (2000), 605-625.

[21] G. SONNEVEND, An "analytic center" for polyhedrons and new classes of global algorithms for linear (smooth, convex) programming, In: Proceedings of the 12th IFIP Conference, Budapest 1985, A. Prekopa, J. Szelezsan and B. Strazicky, eds., Lecture Notes in Control and Information Sciences 84, Springer, Berlin, 1985, pp. 866-876.

[22] S. M. Stefanov, A Lagrangian dual method for solving variational inequalities, Mathematical Inequalities and Applications, 5, (3) (2002), 597-608.

[23] K. TAJI, M. FUKUSHIMA AND T. IBARAKI, A globally convergent Newton method for solving strongly monotone variational inequalities, Mathematical Programming, 58, (1993), 369-383.

[24] N. YAMASHITA, K. TAJI AND M. FUKUSHIMA, Unconstrained optimization reformulations of variational inequality problems, Journal of Optimization Theory and Applications, 92, (1997), 439-456. 